Research Journal of Medical Sciences 4 (3): 227-230, 2010

ISSN: $1815-9346$

(C) Medwell Journals, 2010

\title{
Laboratory Identification of Pulmonary TB Using Simple Rapid Techniques in Osogbo South Western Nigeria
}

\author{
${ }^{1,2}$ O.A. Olowe and ${ }^{1}$ H.B. Famojuro \\ ${ }^{1}$ Department of Medical Microbiology and Parasitology, College of Health Sciences, \\ Ladoke Akintola University of Technology, P.M.B. 4400, Osogbo, Nigeria \\ ${ }^{2}$ Molecular Biology Unit, College of Health Sciences, P.M.B. 4400, \\ LAUTECH, Osogbo, Osun State
}

\begin{abstract}
The study shows laboratory diagnosis of TB. The study tends to evaluate the detection rate of TB in the referral centres under consideration and the relationship of occupation, demographic characteristics, HIV/AIDS and socioeconomic factors to the high incidence of TB using simple laboratory techniques in the environment. Out of 734 cases presented for tuberculosis, 78 (10.6\%) was positive. The age group 16-30 years old had the highest prevalence rate of $(13.1 \%)$ while the least was age group $>75(4.8 \%)$. The effect of tuberculosis with age is not statistically significant $(\mathrm{p}>0.05)$.
\end{abstract}

Key words: Pulmonry TB, socioeconomic factors, detection rate, refferal centers, simple repid technique, Nageria

\section{INTRODUCTION}

Tuberculosis known as (TB) is a major communicable disease that caused serious ill health and deaths in many developed and developing countries in the last decades of 20th century (Murray et al., 1990). TB is a problem of global importance. Despite longstanding intense efforts to conquer pulmonary tuberculosis, this disease remains an expanding global health crisis. Among communicable diseases, TB is the 2nd leading cause of death worldwide, killing nearly 2 million people each year (Frieden et al., 2003).

It is a disease beyond borders able to pass through many international borders unnoticed or unchecked as a result of migrations, epidemics, wars and uncontrolled increase in world population. It remains a serious public health problem in developing countries where its incidence is increasing as a result of poverty, malnutrition, overcrowding and deficient health care (Ankrah, 1997). According to the World Health Organization (WHO), about 8.8 million individuals develop active TB disease every year, of which $95 \%$ live in developing countries. An estimated 1.6 million people die from TB every year (WHO, 2007).

The registered number of new cases of TB worldwide roughly correlate with economic conditions, the highest incidence are seen in those countries of Africa, Asia and Latin America with the lowest Gross National Products. In Nigeria, TB is common; a prevalence of $9.2 \%$ has been reported in one study and a case fatality rate of $12 \%$ in $1 \mathrm{sec}$ (Salami and Oluboyo, 2002). According to the WHO (2007)'s report on global TB control, $44 \%$ of the new TB cases in 2006 were sputum smear-positive cases (SS+) cases. Since 2002, DOTs (Directly Observed Treatment, short course) coverage has increased rapidly from $55 \%$ in $2002-75 \%$ in 2006 and subsequently, the total notified cases of all forms of TB nearly doubled from 38,628 in 2002-70, 734 in 2006. However, only $56 \%$ were SS+. The above shows that our laboratory diagnosis has not measured up to the clinical diagnosis of TB.

This study tends to evaluate the detection rate of TB in the referral centres under consideration and the relationship of occupation, demographic characteristics, HIV/AIDS and socioeconomic factors to the high incidence of TB using simple laboratory techniques in the environment.

\section{MATERIALS AND METHODS}

Study area: Retrospective study was carried out in two health hospitals namely Ladoke Akintola University of technology teaching hospital and Osun state hospital which was both located in Osogbo metropolitan city, the state capital of osun state. It was carried out between January 1-December 31, 2008. Osogbo is situated in the tropical rainforest belt of south western part of Nigeria with about $500 \mathrm{~km}$ from Abuja the Federal Capital

Corresponding Author: H.B. Famojuro, Department of Medical Microbiology and Parasitology, College of Health Sciences, Ladoke Akintola University of Technology, P.M.B. 4400, Osogbo, Nigeria 
Territory. It lies approximately on Latitude $40^{\circ} \mathrm{N}$ of the equator and Longitude $7.34^{\circ} \mathrm{E}$ of the Greenwich meridian and about $1100 \mathrm{~m}$ above the sea level.

Data collection and analysis: The data was collected from the person in charge of the unit in accordance to written permission obtained from the Osun State supervisor of Tuberculosis and Leprosy Control and the representative of LAUTECH Teaching hospital as regards TB cases. The method employed to stain the patients smears were also collected which is Ziehl Neelsen Staining Technique as recommended by WHO (2004). A routine visit was made to the two hospitals within the stipulated period in order to have complete data. The Info-two SPSS, chi-square and multiple range test in order to determine the level of significant $p>0.005$ is taken as non significance.

\section{RESULTS AND DISCUSSION}

The expected results of acid fast bacilli appear as red, beaded rods on a blue background which confirmed the identity of the strains Mycobacterium tuberculosis. The total distribution of sputum-smear results among patient attending the two health institutions by age is shown in Table 1. Out of 734 cases presented for tuberculosis, $78(10.6 \%)$ was positive. The age group 16-30 years old had the most prevalence rate of $(13.1 \%)$ followed by age group $31-45$ years old $(13 \%)$ while the least was age group $>75(4.8 \%)$. The effect of tuberculosis with age is not statistically significant $(\mathrm{p}>0.05)$. Table 2 shows the total distribution of sputum-smear results in relation to sex. Males (12.3\%) were more infected than females $(9.1 \%)$ $(p>0.05)$. Table 3 show the total distribution of sputum-smear results among patients from the two health institutions.

Ladoke Akintola University Teaching Hospital had the highest prevalence rate of $(22.3 \%)$. The histogram shows the total distributions of sputum-smear results among patients attending the two health institutions in Fig. 1. The symptoms of tuberculosis are initially similar to those of other diseases and it is not usually for patients to consider that the problems would be simple to treat or resolve spontaneously. The Acid Fast Bacilli (AFB) smear is a rapid, economical and practicable test for bacteriological diagnosis of tuberculosis because of the expensive turn-around time for mycobacterial culture (Joh et al., 2007). The result obtained from this study indicate that the number of tuberculosis cases tested and registered in the two tertiary health institution in Osogbo is $(10.6 \%)$ which is a little lower than $(21.3 \%)$ in the report of Bassey et al. (2005). This could be as a result of geographical location and climatic factors within the study area. Bassey et al. (2005) conducted their research in Federal Capital Territory Abuja while this particular project was carried out in Osogbo, Osun State. Out

Table 1: Total distribution of sputum-smear results among patient attending the two health institutions by age

\begin{tabular}{|c|c|c|c|c|c|c|c|c|c|}
\hline \multirow{2}{*}{$\begin{array}{l}\text { Age } \\
\text { group } \\
\text { (years) }\end{array}$} & \multicolumn{3}{|l|}{ New cases } & \multicolumn{3}{|l|}{ Old cases } & \multicolumn{3}{|l|}{ Total } \\
\hline & No. of examined & No. of positive & Positive $(\%)$ & No. of examined & No. of positive & Positive $(\%)$ & No.of examined & No. of positive & Positive $(\%$ \\
\hline $1-15$ & 26 & 2 & 7.7 & 9 & 0 & 0.0 & 35 & 2 & 5.7 \\
\hline $16-30$ & 174 & 30 & 17.2 & 85 & 4 & 4.7 & 259 & 34 & 13.1 \\
\hline $31-45$ & 161 & 23 & 14.2 & 55 & 5 & 9.1 & 216 & 28 & 13.0 \\
\hline $46-60$ & 103 & 9 & 8.7 & 34 & 0 & 0.0 & 137 & 9 & 6.6 \\
\hline $61-75$ & 59 & 3 & 5.1 & 7 & 1 & 14.2 & 66 & 4 & 6.1 \\
\hline$>75$ & 19 & 1 & 5.2 & 2 & 0 & 0.0 & 21 & 1 & 4.8 \\
\hline Total & 542 & 68 & 12.5 & 192 & 10 & 5.2 & 734 & 78 & 10.6 \\
\hline
\end{tabular}

$\chi^{2}=7.63, p=0.178$

Table 2: Total distribution of sputum-smear results among patients attending the two health institutions by sex New cases Old cases Total

Sex No. of examined No. of positive Positive (\%) No. of examined No. of positive Positive (\%) No.of examined No. of positive Positive (\%)

\begin{tabular}{|c|c|c|c|c|c|c|c|c|c|}
\hline \\
\hline Males & 255 & 40 & 15.7 & 104 & 4 & 3.9 & 359 & 44 & 12.3 \\
\hline Females & 287 & 28 & 9.8 & 88 & 6 & 6.8 & 375 & 34 & 9.1 \\
\hline Total & 542 & 68 & 12.5 & 192 & 10 & 5.2 & 734 & 78 & 10.6 \\
\hline
\end{tabular}

$\chi^{2}=2.49, \mathrm{P}=0.114$, No $=$ Number, $\%=$ Percentage

Table 3: Total distribution of sputum-smear results among patients from the two health institutions New cases Old cases Total

Health $\quad$ - New cases $\begin{array}{lccccccc}\text { institution } & \text { No. of examined } & \text { No. of positive } & \text { Positive (\%) } & \text { No. of examined } & \text { No. of positive } & \text { Positive (\%) } & \text { No.of examined } \\ \text { LTH } & 147 & 30 & 20.4 & 10 & 5 & 50 & 157\end{array}$

\begin{tabular}{|c|c|}
\hline OS & 395 \\
\hline
\end{tabular}

\begin{tabular}{llllllll} 
Total & 542 & 68 & 12.5 & 192 & 10 & 5.2 & 734 \\
\hline
\end{tabular}




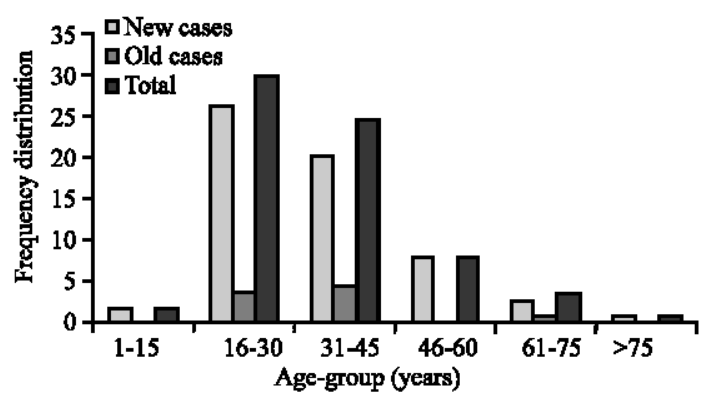

Fig. 1: Frequency distribution of sputum-smear results among patients from the two health institutions by age

of $78(10.6 \%)$ positive cases, $68(12.5 \%)$ were new cases and $10(5.2 \%)$ were old cases. The incidence of tuberculosis in developing countries has continued to increase despite the efforts of control programmes. This has been attributed to several factors including poverty, HIV burden and lack of resources for effective and rapid diagnosis of the disease in these areas. The highest prevalence of sputum smear positivity (13.1\%) was found in those age group 16-30 years old and that is in agreement with published data that tuberculosis is a disease of the productive population (Snider and Montagne, 1994). Risk factors for the high incidence of tuberculosis in their population include poor condition of living (overcrowding) especially in urban areas, lowered immunity due to $\mathrm{HIV}$ with consequent reactivation of primary infection. The Rate of Smear Positivity Ranging from 5.7 (children)-10.9\% (adults), falls within the range of previous published data. As low as 9-46\% smear positivity has been reported for some laboratories in African country (Aber et al., 1980).

The low sputum-smear-positivity rate associated with this finding and other studies may be attributed to the lack of sensitivity of the method used (Aber et al., 1980; Wilkinson et al., 1997). Infection with HIV may also reduce the diagnostic sensitivity of the direct smear method (De Cock et al., 1992). The sex distribution was investigated and found that males $(12.3 \%)$ were more infected than females $(9.1 \%)$. This disagreed with the report of Homes. This could be as a result of social, religious, economic and political factors. Overcrowding and smoking habit of most males population may be attributed to high prevalence. This study has a number of limitations including those necessitated by the limited time available and access to key informants. Tuberculosis and HIV care and prevention require the collaboration of many partners. However, evidence of effective collaboration between TB and HIV programme is scarce. This study suggests that TB and HIV programs need to collaborate to deliver an effective response to $\mathrm{HIV}$ related TB. Improving the diagnostic sensitivity of sputum smear microscopy would improve case detection while wealthy industrialized countries with good public health care systems can be expected to keep TB under control, in much of the developing world like Nigeria, a catastrophe awaits.

The use of cultures or more rapid and modern techniques may not be feasible in countries with poor resources like Nigeria. Sputum smear examination for acid fast bacilli may still remain the cheapest and most prognostic method.

Therefore, methods to improve the diagnostic sensitivity of Ziehl-Neelsen smear should be put in place and else more awareness of tuberculosis and HIV should be geared up by mass campaign among the health sectors so that menace would reduce drastically.

\section{CONCLUSION}

In conclusion, it is crucially important that support be given to research efforts devoted to developing an effective TB vaccine, shortening the amount of time required to ascertain drug sensitivities improving the diagnosis of TB and creating new, highly effective anti-TB medications. Without support for such efforts, researchers run the risk of losing the battle against TB.

\section{REFERENCES}

Aber, V.R., B.W. Allen, D.A. Mictchison, P. Anumo, E.A. Edwards and A.B. Keyes, 1980. Quality control in TB bacteriology: Laboratory studies on isolated positive cultures and the efficiency of direct smear examination. Tubercle, 6: 123-133.

Ankrah, T.C., 1997. The history of tuberculosis and its resurgence in the community. West Afr. J. Med., 16: $1-5$.

Bassey, E.B., M.A. Momoh, S.O. Imadiyi, E.B. Udofia and F.S. Miri et al., 2005. The trend of pulmonary tuberculosis in patients seen at DOTS clinics in the Federal Capital Territory, Abuja, Nigeria. R. Inst. Public Health, 119: 405-408.

De Cock, K.M., B. Soro, I.M. Coulebaly and S.B. Lucas, 1992. Tuberculosis and HIV infection in sub-Saharan Africa. J. Am. Med. Assoc., 268: 1581-1587.

Frieden, T.R., T.R. Sterling, S.S. Munsiff, C.J. Watt and C. Dye, 2003. Tuberculosis. Lancet, 362: 887-899. 
Joh, J.S., C.H. Lee, J.E. Lee, Y.K. Park and G.H. Bai et al., 2007. The interval between initiation of antituberculosis treatment in patients with culturepositive pulmonary tuberculosis and receipt of drugsusceptibility test results. J. Korean Med. Sci., 22: 26-29.

Murray, C.J.L., E. Dejongbe, H.J. Chum, D.S. Nyangulu, A. Salamd and K. Styblo, 1990. Bacterial infection, cost effectiveness of chemotherapy for pulmonary $\mathrm{TB}$ in three sub-Saharan African countries. Infect. Dis. Lancet, 1992: 85-88.

Salami, A.K. and P.O. Oluboyo, 2002. Hospital prevalence of pulmonary tuberculosis and co-infection with human immunodeficiency virus in Ilorin, a review of 9 years (1999-1999). West Afr. J. Med., 21: 24-27.
Snider, Jr. D.E. and J.R.L. Montagne, 1994. The neglected global tuberculosis problem: A report of the 1992 world congress on tuberculosis. J. Infect. Dis., 196: 1189-1196.

WHO, 2004. TB/HIV. A Clinical Manual. 2nd Edn., WHO, USA., pp: 329.

WHO, 2007. Global tuberculosis control: Surveillance, planning, financing. World Health Organization, Report. Geneva, Switzerland (WHO/HTM/TB/2007. 376).

Wilkinson, D., K.M. Decock and A.W. Sturm, 1997. Diagnosing tuberculosis in a resource poor setting: The value of sputum concentration. Trans. R. Soc. Trop. Med. Hyg., 91: 422-424. 